\title{
Politicizing COVID-19 Vaccines in the Press: A Critical Discourse Analysis
}

\author{
Ali Haif Abbas $^{1}$ [D
}

Accepted: 3 July 2021 / Published online: 10 July 2021

(c) The Author(s), under exclusive licence to Springer Nature B.V. 2021

\begin{abstract}
Undoubtedly and unfortunately, COVID-19 pandemic has been politicized in media see Abbas (Int J Semiot Law, 2020), Rui Zhang (Media Asia 48:89-107, 2021). Although vaccines play a crucial role in eliminating the pandemic, they have been politicized by media. This article aims to show how COVID-19 vaccines are politicized in the press. The article collects some selected reports on vaccines taken from American and Chinese media. The reports are analyzed according to an analytical framework suggested by the researcher. The framework and data collection and description are clearly presented in the method section. Based on data analysis, the article shows that COVID-19 vaccines have been politicized. The study recommends that diseases and vaccines should not be politicized. In other words, we should respect and trust science and our scientists for no other purpose than to reach herd immunity and overcome a dangerous pandemic that has taken and is still taking thousands of innocent lives.
\end{abstract}

Keywords Critical discourse analysis $\cdot$ Media disinformation $\cdot$ Herd immunity COVID-19 vaccines

\section{Introduction}

Previous studies demonstrated that COVID-19 has been politicized and used for ideological and political interests [2, 22, 23]. Even the mask which is used to reduce or minimize the spread of the disease infection has also been politicized [15]. Inventing, producing, and exporting a vaccine is not an easy task. Costing billions of dollars and lots of hard and difficult efforts and stages done by experts, volunteers, and pharmaceutical companies, COVID-19 vaccines are unfortunately being politicized and turned into a struggle of political interests.

Ali Haif Abbas

ahaif@uowasit.edu.iq

1 University of Wasit, Wasit, Iraq 
The media which belong to the vaccines-producing countries have started to lunch a series of disinformation campaigns questioning and suspecting the effectiveness of some vaccines over others. In other words, the media use the ideology of positive us representation and negative others representation. The media ideologically use the following overall strategies:

Say good and positive things about our vaccines

Do not say bad and negative things about our vaccines

Say bad and negative things about their vaccines

Do not say good and positive things about their vaccines

This ideological polarization is widely used in media to highlight the positive and good quality and effectiveness of 'our' vaccines on one hand and highlight the negative and bad qualities and effectiveness of others' vaccines.

In the midst of the many challenges surrounding the invention, difficult production, and vaccination, experts argue that achieving immunity protection or what they call it "herd immunity" to overcome and undermine the pandemic requires the vaccination of 70 to 85 percent of the entire population of the planet earth [11] with more than 10 billion doses, which take long time to manufacture and cost tens of billions of dollars. Herd immunity is one good way of protection from infectious diseases. It happens when the entire population is immune either from vaccination or acquiring immunity through previous infection. The World Health Organization (WHO) supports achieving immunity protection through vaccination, not through previous infection since the latter way would result in unnecessary cases and deaths. The percentage of people who need to be immune in order to gain herd immunity varies according to the disease. For example, in order to achieve herd immunity against measles, $95 \%$ of the population needs to be vaccinated. The other 5 percent will be safe from measles by the fact that measles will not spread among the vaccinated population. Vaccines job is to train our immune systems to create proteins (antibodies) which are effective in the fight against the disease. In other words, vaccines are protecting people from getting the disease, passing on the pathogen, breaking any chains of transmission [30]. With all this effort and fatigue resulting from the creation of vaccines and the production of largest number of doses in order to reach herd immunity and save the world from the pandemic, the media, unfortunately, practice different methods of misinformation and disinformation against vaccines. As much as the promotion of Corona vaccines raises optimism that the pandemic will subside, the more it highlights the chronic crisis of confidence that hangs over the international system, as the politicization of vaccines undermines people's confidence in them. In addition to the conspiracy theory and what has been rumored about creating the virus and its vaccines with the aim of reducing the world population or controlling the human genome. All such news aimed at dispelling people's confidence in vaccines. This does not only hinder the herd immunity which is the best way to eliminate the pandemic but also it negatively influences people's economic life. As we all know the fact that the pandemic has negatively influenced economy, especially the poor and low economic countries. 
Under the insane insistence on politicizing the pandemic and its vaccines, it became difficult for most of the people of this world to meet their urgent needs, especially with the increasing number of cases and deaths and the fear from the emerging of a new more deadly mutated strain of the pandemic. This paper aims to show how COVID-19 vaccines are politicized in media and recommends that we should not politicize pandemics and vaccines. On the contrary, we should respect and trust science and our scientists.

\section{Literature Review}

In the late December of 2019, the world witnessed a dangerous emergence of an outbreak in Wuhan, Hubei province, China. Then, China's CDC demonstrated that a novel coronavirus (SARS-CoV) is the main cause of this outbreak. The disease was, then, named as novel coronavirus disease 2019 (COVID-19) [10]. On January 30, 2020, the World Health Organization (WHO) declared that COVID-19 is a "public health emergency of international concern" [9]. COVID-19 cases and deaths have been spread quickly across the planet to reach by the end of May, 2020, more than 6 million infected cases and more than 369,000 deaths across the globe [6]. At present time, the total cases of COVID-19 reaches more than 166, 148, 800 infections with more than 3, 443, 190 deaths according to the latest updates of Johns Hopkins University.

Politicizing pandemics is not a new-bad habit that humans should get rid of. History proved the fact that endemics and pandemics were politicized and used for manipulative, political, and ideological interests [2]. Amid the rapid spread of COVID-19 with its increasing cases and deaths, politicians and media response to the vaccines is ideological without putting into consideration that such news coverage can influence public attitudes towards the vaccines since such news will definitely impede the way to reach herd immunity to eliminate the pandemic and save the world.

Abbas [2] demonstrates that the media play a significant role in shaping the world and framing its crucial events, crises, and problems:

The broadcast and print media have a very big influence on public opinion and they are major channels for communication between decision makers and the public. The power of the media stems from its influence on the crystallization of our thoughts. Thoughts serve like an engine which drives and controls our actions and behaviour. The media have the ability to work day and night for the purpose of forming perceptions, manipulations, and changing convictions, regardless of whether it is a positive or negative change, acceptable or rejected, beneficial or harmful, beloved or hated

Media and social media disinformation and misinformation regarding the origins of the pandemic and the efficacy of the vaccines push WHO to stress the necessary need for fighting infodemics on one hand and trusting and respecting science on the other. WHO emphasizes that infodemics includes deliberate attempts to disseminate 
wrong information to undermine the public health response and advance alternative agendas of groups or individuals [31]. While COVID-19 continues to spread quickly across the globe, vaccine hesitancy is widespread. Therefore, encouraging campaigns for the crucial need of vaccination are needed in order to reach immunity protection [17]. Ideological news, disinformation, and anti-vaccine propaganda are not new issues; instead they date back more than a century [16, 26, 33]. Researchers have found out that there is a clear connection between political beliefs and attitudes towards vaccines. Scientific organizations and scientists face major difficulty in clarifying the fact that recommending a vaccine comes from scientific knowledge rather than political beliefs or interests. This problem becomes worse in the present time of the pandemic. Considerable scientific uncertainty, limited effect of science over politics, and politicians, not experts, are the public face of crisis management [8].

The Director-General of the World Health Organization (WHO), Tedros Adhanom Ghebreyesus said "We're not just fighting an epidemic; we are fighting an infodemic" [32]. It is, therefore, crucial for the media to present best information with credible sources free from disinformation, ideological, and political interests. This article aims to show instances of ideologies in vaccine news and how some vaccines are represented positively, while other vaccines are represented negatively.

\section{Method}

The data consist of (4) selected reports taken from two newspapers namely, Global Times from China and The New York Times from the United States of America (US). Two selected reports are taken from the Chinese newspaper and the other two reports are taken from the American newspaper. The selected reports are analyzed according to four discourse strategies namely, lexicalization, transitivity, evidentiality, and clause complexing. The selected four discourse strategies can be invested ideologically to save the interests of language users. They can also be used to uncover hidden ideologies and power relations in discourse.

\section{Lexicalization}

Lexicalization is a powerful tool that can be used ideologically to save certain interests of language users. Van Dijk [27] demonstrates that "the major dimension of discourse meaning controlled by ideologies is the selection of word meaning through lexicalization" ( $p, 259)$. Lexicalization is a powerful ideological strategy which plays a crucial role in the positive representation of certain things and the negative representation of other things.

Emphasize our positive things

De-emphasize our negative things

Emphasize their negative things

De-emphasize their positive things [28] 
Media owners and politicians always employ positive lexical items when they describe themselves and their acts, while they employ negative lexical items when they describe others and their negative acts towards sensitive and problematic issues in societies and across the globe. In other words, they represent a complex of ideologies [21]. Such ideologies (a set of ideas and beliefs) are accepted by some groups or people but unaccepted by other groups or people.

Min [20] states that:

The choice of words is important in providing readers with cues for interpreting events. It can define how we perceive the actions and the intentions of the participants in events, and thereby convey the message that the producer of the text intended readers to receive. Lexical items construct particular ideological representations of experiences or events. Apart from this experiential function, vocabulary has expressive value implying the producer's negative or positive evaluation of actions, participants, and events. Therefore, the structure of vocabulary can be regarded as ideologically based. The selection of wordmeanings through lexicalization is one of the major dimensions of news discourse fashioned by ideologies (152).

The choice of certain lexical items or vocabulary reflects the speaker's or writer's attitude towards a sensitive issue in a society. Therefore, ideologies can be clearly discovered or seen in media texts through the choice of lexical items. Human perceptions, ideas, beliefs, and ideologies can be effectively conveyed through the use of lexicalization $[12,19]$.

\section{Transitivity}

Transitivity, as an ideological discourse strategy, is crucial for the current study since it is important to show how vaccines are described and represented in terms of processes and participants.

Halliday [14] illustrates that transitivity "construes the world of experience into a manageable set of process types" (106). Simpson [25] demonstrates that transitivity is concerned with how meaning is represented in the clause. In other words, it shows how speakers and writers encode in language their mental picture of reality and how they account for their experience of the world around them. Transitivity is concerned with the clause as its unit of analysis [13]. A clause consists of a process and participants involved in it and the circumstances surrounding the process [5]. Halliday [14] classifies processes into six types. Each process has its own participants. They are: material processes (processes of doing, happening, and changing). Participants of the material processes are actors (those who do) and goals (those who are effected by the actions of the actors). Mental processes are processes of feelings, thinking, seeing. Participants who perform the senses are called "sensors". Relational processes are processes of being-having an attribute or identity with a participant called "identified". Verbal processes are processes of saying, promising, warning, talking. Participants who say something are called "sayers". Behavioural processes are processes of behaving (laughing, crying, and smiling). Participants 
who perform behaving are called "behavers". Existential processes are processes of place, location, and being there. Participants who perform this process are called "existents".

\section{Expanding Clause Complexing}

Expansion of a clause is also crucial for this study to show how certain clauses are expanded with more information rather than others. Expanding of a clause can be done by three ways: elaboration (giving more contextual details and more emphasis to certain topics, mentioning the same topic again and over again either by repetition or rewording or by giving more examples and illustrations. The code used for this expanding way is equal (=) as in Italians = people who live in Italy. Extension is used to refer to the addition of new information to the topic in question. Extension extends a clause by adding alternative information or exception usually preceded by conjunctions such as and, but, than, for example as in John can drive very nicely and he also plays the piano very well. Enhancement means enhancing a clause by a number of enhancing relations such as time, place, cause, manner, and condition. In enhancement, a clause enhances another by decorating it with so, yet, then [3].

\section{Evidentiality}

Evidentiality is concerned with the way a speaker or writer qualifies statements by referring to the information source and the degree of reliability of the information source on which the statement is based. When speakers and writers convey a statement, they must indicate the type of source on which such a statement is based. This source of information might be directly heard, seen or might be inferred or deduced from indirect evidence or might be learnt from other people [1, 4, 18, 24$]$.

Van Dijk [29] illustrates the role of evidentiality in arguments or sensitive issues:

Claims or points of view in argument are more plausible when speakers present some evidence or proof for their knowledge or opinions. This may happen by references to authority figures or institutions, or by various forms of evidentiality: How or where did they get the information. Thus people may have read something in the paper, heard it from reliable spokespersons, or have seen something with their own eyes. Especially in debates on immigration, in which negative beliefs about immigrants may be heard as biased, evidentials are an important move to convey objectivity, reliability, and hence credibility. In stories that are intended to provoke empathy, of course such evidence must be supplied by the victims themselves (736).

Chafe [7] lists different modes of knowledge evidentials: belief (in belief mode of knowledge, the evidence is downgraded. People believe in things because they respect those who say these things), induction (reaching a conclusion through inference), direct sensory and hearsay evidence (direct sensory evidential markers such as see, hear, taste, smell indicate reliable knowledge), indirect sensory and hearsay 
evidence (when one takes or conveys the information from another one an indirect way), deduction (using reason and hypothesis to form a conclusion or opinion about something), hedges (expressions such as sort of, kind of, about, approximately), and expectations (evidential markers that are used to refer to a belief that something will happen or likely to happen such as in fact, but, nevertheless, actually, of course, at least, oddly, enough, however, even (Fig. 1).

\section{Data Analysis}

This section is concerned with the analysis of the selected news reports on COVID19 vaccines which are taken from the two newspapers namely, Global Times and The New York Times. The selected reports are analyzed according to the four discourse strategies namely, lexicalization, transitivity, evidentiality, and clause complexing.

\subsection{Global Times News Analysis}

In this section, the two news reports are analyzed according to the quadrant analytical framework.

\subsubsection{Report 1}

The report starts with the following headline "Why were US media silent on Pfizer vaccine deaths?" The lexical item "Pfizer" is used to refer to the American company which invented and produced and is still producing a vaccine against COVID-19. The negative other representation can be clearly seen from the headline (Pfizer vaccine deaths). In the phrase, the word vaccine is preceded by the name Pfizer which clearly refers to an American origin and followed by the word "deaths" in the plural form which negatively denotes losing many lives. In other words, the lexis "Pfizer" is associated with deaths. The headline is completely negative towards Pfizer vaccine (Table 1).
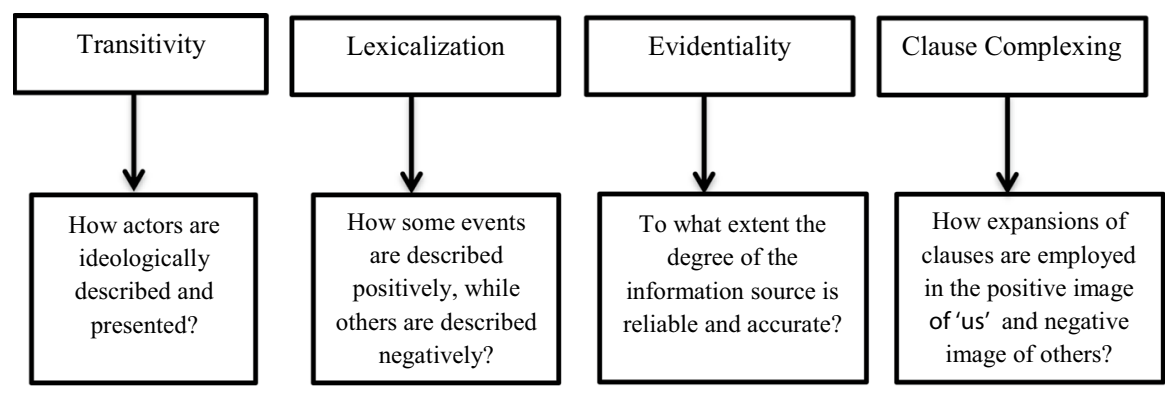

Fig. 1 The adopted quadrant framework for the analysis of the selected data 
Table 1 Global times report 1 summary

\begin{tabular}{ll}
\hline Headline & Why were US media silent on Pfizer vaccine deaths? \\
Length & 796 words \\
Key features & $\begin{array}{c}\text { The report focuses on the negative representation of } \\
\text { US media, government, and Pfizer vaccine on one } \\
\text { hand, and the positive representation of Chinese } \\
\text { government and Chinese vaccines on the other }\end{array}$ \\
\hline
\end{tabular}

The report starts with the following introduction "Twenty-three elderly Norwegian people died after receiving Pfizer vaccine". This emphasizes the negative effects of Pfizer vaccine on people. The noun "people" is modified by three expansions: the adjective Norwegian which identifies their nationality, the adjective elderly which illustrates that the people are old, and the number twenty-three. The people are described as weak goals for the powerful negative actor "Pfizer". Pfizer is described as a powerful actor causing death and killing twenty-three people in Norway. Clause expansion strategy makes everything clear in the clause including the number of the dead people, the place, the causes, and the time (after receiving Pfizer vaccines). The conjunction "and" in the clause (Thirteen of them have been assessed and common side effects may have contributed to severe reactions in them) is used as a function word to express supplementary explanation and connection of two items or issues. The additive information after the conjunction "and" is used to emphasize that the main cause behind their death is Pfizer and its side effects.

In the report, Norway is identified as a small Northern European country not for geographical reasons but for ideological reasons. Consider the compound sentence which is linked by "and" (Norway is a small Northern European country and only about 25,000 people have been vaccinated with Pfizer vaccines). The additive "and" with the clause (only about 25,000 people have been vaccinated with Pfizer vaccines) are used to emphasize that the number of people who have been vaccinated with Pfizer is a small sample. Number game is a persuasive strategy that can be invested ideologically by language users. The small number of the 25,000 people who have been vaccinated with Pfizer in a small country like Norway came out with negative results; with twenty-three deaths as the newspaper puts it (Twentythree deaths are a large number). The word "but" is used to express a contradictory idea, with the previous one which is concerned with Pfizer deaths, in the clause (But surprisingly, mainstream English-language media did not report the incident immediately, as if they had already reached a consensus). The expanding words "English" and "language" in "mainstream English language media" are deliberately used to refer to the US and UK media. The word "consensus" which means "a general agreement" refers to the US and UK media general agreement about a negative thing not a positive thing. According to Global Times, the US and UK media did not report the negative side effects and deaths of Pfizer. The use of the past perfect simple with the past simple tense is dramatic. The past perfect simple is used to express an action or event taking place before a certain time in the past. According to Global Times, the US and UK media agreed previously to not report and de-emphasize the negative effects and deaths of their vaccines including Pfizer. Global Times keeps on 
attacking Western media. According to Global Times, Western media de-emphasize and do not report the negative effects of their vaccines but they ideologically invest any negative information about Chinese vaccines. Consider this quotation: (In contrast, those major Western media will immediately hype any unfavorable information about Chinese vaccines and try to amplify their impact on public psychology. For example, the data of China's Sinovac vaccine was lower than expected in Brazil, and it was reported everywhere in Western media. The death of a Brazilian volunteer who participated in the trials also became a major event in Western media. But it was later proven that the death had nothing to do with the vaccination, and Western media lost their interest). The expression "in contrast" is used to strengthen Western media deliberate negative statement on Chinese vaccines. The lexical items "hype and "amplify" connote exaggeration, hyperbole, lies, and deception. They are used to refer to western media regarding their deliberate and dishonest negative news on Chinese vaccines. The word "for example" is not used by Global Times to emphasize China's Sinovac vaccine lower data in Brazil but to emphasize the exaggeration and lies of western media. The conjunction "but" with the additive "and" are used to negate western media news which deliberately emphasizes the death of a Brazilian volunteer due to Chinese vaccine. According to Global Times, the death has nothing to do with Chinese vaccine. Global Times identifies COVID-19 vaccine as serious scientific issue. This implies that vaccine should not be politicized and here global Times refers to the US and UK media politicization of corona vaccines. The current pandemic situation is identified as "extremely critical". According to Global Times, people need to have more vaccines to fight the disease. In the clause (However, some mainstream US and British media are taking the lead in putting geopolitical labels on vaccines), the word "however" is used to emphasize a contrast. Although the world needs to be vaccinated to fight COVID-19, US and UK media are working against this positive and crucial thing. The use of the progressive aspect such as taking the lead, putting geopolitical labels on vaccines, meddling in political stances, using their propaganda to promote Pfizer vaccines, smearing Chinese vaccines are negatively used to represent US and UK media and to emphasize their continuous negative acts against humankind in their politicization of vaccines.

Global Times assigns negative qualities to Pfizer vaccine, while it assigns positive qualities to Chinese vaccines. Consider this quotation: (If there needs to be some comparison, then China's inactivated vaccine definitely has more solid foundation in safety than Pfizer's mRNA vaccine. The inactivated vaccine technology has been very mature and has undergone decades of clinical testing. But it is the first time that the mRNA technology was applied to the vaccine. This large-scale promotion of Pfizeri's vaccine is a continuous process of large-scale testing on human beings). The comparison is ideologically chosen by Global Times. Starting with the possessive form "Chinese inactivated vaccine" which is used to highlight that the vaccine is totally invented and made by China, while the newspaper refers to the other vaccine as "Pfizer", Pfizer is American company along with the German BioNTech invented the vaccine. There is a tendency from Global Times to emphasize that Pfizer is not totally US invention. The adverb "definitely" means (in a definite way: in a way free of all ambiguity, uncertainty, or obscurity; used in speech as a forceful way of expressing agreement about something). Using factual adverb like 
"definitely", Global Times emphasizes that China's inactivated vaccine is safer than Pfizer's mRNA vaccine. In addition to its safety, China's vaccine adopts an old technology which has undergone long time of clinical testing. The word "but" is used to emphasize a contrast to the previous story. Pfizer's mRNA vaccine adopts the first time technology which still needs large continuous testing on human beings. Aristotelian ethos is clearly used in Global Times comparisons between China's vaccine and Pfizer vaccine. The positive representation of China's vaccine and the negative representation of Pfizer vaccine can be obviously seen. Global Times attempts to persuade the public that China's vaccine is safer and better than Pfizer by mentioning the inactivated vaccine technology which is, according to the newspaper, older and safer. Pfizer vaccine always associated with risks, dangers, and deaths. In the two clauses (Even if there are risks, these countries would rather bear them. As long as they can save the lives of most people, they would accept the pros and cons), the conditional clauses are used to stress that something will happen despite something else that might prevent it. In other words, due to vaccination reasons, US will use Pfizer vaccine even if it causes risks and deaths. These two clauses are enough to cause total fear and panic in people's minds from Pfizer risks. The twenty-three deaths in Norway have been immediately repeated to emphasize the risks of Pfizer vaccine on people's lives.

Us and UK media are always described negatively in Global Times. They are associated with negative lexical items such crude double standards, unhealthy mindset, downplaying, and partiality. Western media are described as a powerful actor attacking and smearing China partially, downplaying Pfizer deaths and risks, and politicizing vaccines which are a scientific issue. This negative representation of the West is met with positive representation of China. According to Global Times, Chinese government and Chinese society are positive actors putting science and objectivity as priorities. The newspaper presents Chinese senior officials positively and objectively in their refuse to endorse or praise Chinese vaccines. According to the newspapers, most and many praises are coming abroad from many leaders of developing countries. The newspapers emphasizes that most phase III trials happened abroad - outside China. More contextual details, emphasis, positive lexical items are given to China and Chinese vaccines. The use of "most" in (most praises of China's vaccines are from abroad) and the use of "many" in (Many leaders of developing countries have taken the lead in injecting Chinese vaccines based on their countries' data of Phase III trials) give the statements a generic agreement and legitimacy about the safety and effectiveness of China's vaccines. Clause expansion strategy is also invested ideologically in Global Times report. When the story is related to China and China's vaccines, the newspaper uses positive expansions adding more positive information but when the story is related to Pfizer vaccine and western media, clause expansion is used negatively adding negative information: (However, the Pfizer vaccine has been strongly promoted by the US administration and capital. Their potential risk has been deliberately downplayed by Western public opinion. And public opinion has created an impression that Pfizer's mRNA vaccine, which is being used for the first time, is safer than the Chinese vaccine). The use of the passive voice is to give more emphasis to Pfizer risk which is deliberately downplayed by Western media. The expanding clause (which is being used for the first time) is 
ideologically chosen to emphasize the idea that Pfizer is not safe and effective. This clause itself puts bad impression and reaction towards Pfizer.

Washington, which is a metonymic word that stands for the United States, is described as a powerful negative actors promoting confrontation and initiating ideological frenzy against China. The word "frenzy" means (a temporary madness, intense, wild, and compulsive or agitated activity). The word is used to refer to the US. The report ends with Global Times urging, through using powerful material verbs, the Chinese to face the ideological confrontation, defend China's national interests, and support their own country.

\subsubsection{Report 2}

This report starts with the headline: China's vaccines better suit Africa, LatAm due to 'lower costs, easier logistics'. The previous report focuses on China's inactivated vaccines in terms of safety and effectiveness, which according to Global Times, are better in safety and effectiveness than Pfizer. It is clear from the headline that this report focuses on the positive representation of China's vaccines and the negative representation of US vaccines in terms of two important things which Global Times invested ideologically: vaccine costs and logistics (Table 2).

In the first paragraph, Global Times argues that African and some Latin American countries prefer (Chinese-developed inactivated vaccines, due to their competitive costs and easier logistics, to stop their pandemic crisis, said analysts in both the vaccine and drug transportation services). The actors namely, African and other Latin-American countries prefer "Chinese-developed inactivated vaccines". The expanding clause complexing (due to their competitive costs and easier logistics) is ideologically chosen by Global Times to emphasize the preference of Chinese vaccines over other vaccines in terms of lower costs and easy logistics which are two crucial factors in any vaccine. In terms of evidentiality, the indirect hearsay evidence is used. These kinds of evidential markers do not show high degree of reliability in the information source since it is taken from another source indirectly. This gives readers a sense of disbelief and suspicion in the Global Times statement which stresses that African and some Latin-American countries prefer China's vaccines. The analysts are not even given names and this raises much suspicion in the readers' mind. More positive contextual details are given to Chinese vaccines, while more negative contextual details are given to US vaccines. The report is full of

Table 2 Global times report 2 summary

\begin{tabular}{ll}
\hline Headline & China's vaccines better suit Africa, LatAm due to 'lower costs, easier logistics' \\
Length & 638 words \\
Key features & The report focuses on the positive representation of China's vaccines and the \\
& negative representation of US vaccines. According to Global Times, China's \\
inactivated vaccines have lower costs and simple logistics than the compli- \\
cated mRNA technology in Pfizer and Moderna vaccines. Due to their lower \\
costs and simplicity, China's vaccines are better suit poor African and Latin \\
- American countries than the expensive and complex US vaccines
\end{tabular}


comparisons. In this report, Global Times always says positive things about Chinese vaccines and says negative things about US vaccines. The newspaper also emphasizes the negative things of US vaccines but it never mentions the negative things of Chinese vaccines. Polarizations of US vaccines and ideological negative representation are widely used in the report. According to Global Times, US vaccines are complex associated with ineffectiveness, unproductiveness, and weakness. US vaccines are described as weak actors unable to resist tropical heat, low temperatures, and poor electricity, especially in poor African and Latin-American countries. Global Times emphasizes the idea that US vaccines need high sophisticated storage conditions which cannot be available in poor countries. Metaphorical hyperbole is widely used in this report. According to Global Times, Pfizer and Moderna are money; do not suit poor countries due to their high costs. Poverty game is skillfully employed by Global Times emphasizing that most poor countries not only cannot pay for such costly vaccines but also they are unable to provide sophisticated technology for such vaccines (considering the challenges facing the recipient countries in importing Western mRNA vaccines such as tropical heat, distance and the scarcity of ultra-cold freezers required by US producers). China's vaccines on the other hand are presented positively in the report. They are effective, less costly, better suit poor countries, and do not need complex transportation and storage conditions like US vaccines. Transitivity is used ideologically by Global Times. In addition to the material processes which represent US vaccines as weak actors, expensive, not suit poor countries, and complex in transportation and storage conditions while they represent China's vaccines as powerful actors able to stop the pandemic crisis, cheap, better suit poor countries, and simple and easy in logistics, Global Times makes use of verbal processes and sayer participants. Chinese experts, medical analysts, and officials are represented as powerful sayers of truth regarding both the weaknesses of US vaccines and the preferences of China's vaccines. The reason behind choosing Chinese experts by Global Times is to emphasize the negative representation of US vaccines and the positive representation of Chinese vaccines. In this report, Global Times picks sayers that say bad things about US vaccines on one hand and say good things about Chinese vaccines. In the whole report, experts said, medical analysts suggest, analysts said good things about Chinese vaccines. They never say bad things about Chinese vaccines. They always say bad things about US vaccines. They do not say good things about US vaccines. Consider this quotation which represents Chinese experts as powerful sayers of truth about the bad US vaccines and the good Chinese vaccines (medical analysts suggest that Chinese inactivated vaccines are favored for mass inoculation in Africa, as China-developed inactivated vaccines can be delivered by off-grid refrigerators, which do not require advanced electricity, Chen Yong, manager of the Lengwang Technology Co., which provides cold-chain solutions for traditional medical product logistics, told the Global Times on Tuesday. On the contrary, vaccines from Pfizer and Moderna rely on mRNA technology which needs to be stored at around minus 70 degrees Celsius and minus 20 degrees, respectively. Such a requirement presents a challenge for African and Latin American countries, where poor electricity infrastructure cannot support the ultracold freezers during transport, Chen said). Evidentiality is a powerful strategy that can show whether the information source is accurate or ideological. After skillfully 
reading the report, I notice that all the evidential markers used by Global Times are that of indirect hearsay evidentials such as experts said, analysts said, medical analysts said, the expert said, a Beijing-based vaccine expert who requested anonymity told the Global Times on Tuesday, experts suggested. Such indirect evidential markers give the reader a feeling of doubt and disbelief. Most of the sayer participants are not given names. They remain anonymous. This is a weakness in the degree of reliability of the information source, especially when they negatively talk about US vaccines. Global Times only mentioned three Chinese experts (Chen Yong, manager of the Lengwang Technology Co, Xu Xin, a director of the Beijing Biological Products Institute of Sinopharm, Tao Lina, a Shanghai-based vaccine expert). Those experts always say negative things about US vaccines such as Pfizer and Moderna. Chinese sources are always used as primary definers of the situation. They definitely say positive things about Chinese vaccines and this is not accepted from an evidential perspective.

\subsection{The New York Times Reports}

This section is concerned with the analysis of the selected New York Times news stories on Chinese vaccines.

\subsubsection{Report 1}

The report starts with the headline: Disappointing Chinese vaccine results pose setback for developing world. The headline is important in telling readers what the whole news story is about. Through the negative headline, one can infer that the whole news story is negative towards Chinese vaccines. The headline represents the Chinese vaccine as a powerful negative actor posing "setback" for developing countries. The word "setback" is negatively used to describe the Chinese vaccines. Instead of making progress and helping developing countries in overcoming the disease, the Chinese vaccines are "setback" causing delay or stopping progress (Table 3).

The New York Times gives more details and emphases to the negative representation of Chinese vaccines, especially CoronaVac. Many negative lexical items are used to describe Chinese vaccines and their low efficacy against COVID-19. In the report, Chinese vaccines are always associated with lowness and weakness to protect people from the risks of the pandemic. Negative lexical items such as diminishing hopes, shorter or less effective, lower efficacy, a cause for concern, weaker efficacy, tepid

Table 3 The New York times report 1 summary

\begin{tabular}{ll}
\hline Headline & Disappointing Chinese vaccine results pose setback for developing world \\
Length & 1,440 words \\
Key features & The report focuses on the negative representation of Chinese vaccine \\
& and its old technology and low efficacy on one hand and the positive \\
& representation of US vaccines on the other
\end{tabular}


results are skillfully chosen to negatively represent the Chinese vaccines. The two negative sides of the ideological square are widely used in the report. In other words, The New York Times always says negative things about Chinese vaccines and does not say positive things about Chinese vaccines. On the contrary, the other two positive sides of the ideological square are also used to positively represent US vaccines. In other words, The New York Times always says positive things about US vaccines and does not say negative things about US vaccines (The lower efficacy announced Tuesday would mean it would take longer for countries that used CoronaVac's vaccine to reach "herd immunity," the point at which enough people are resistant to the virus-roughly 70 percent, many scientists have said - that it is vanquished in a population. By contrast, the vaccines made by Moderna and Pfizer-BioNTech have been shown to have an efficacy rate of about 95 percent). Transitivity system is skillfully and ideologically employed by the newspaper to negatively represent Chinese vaccines. The choice of processes and participants is ideological and manipulative. Chinese vaccine "CoronaVac" is described as a weak actor made in China. CoronaVac is identified as a weak actor with low efficacy rate unable to provide full protection from COVID-19. But US vaccines are described as powerful actors having an efficacy rate of about 95 percent. The older technology which most of the Chinese vaccines rely on is identified as a negative actor that can weaken a vaccine's potency, not strengthening it, and this leads in an immune response that could be shorter or less effective. Using relational process, many of the countries which have ordered CoronaVac are identified as poor and desperate in controlling the pandemic and protecting their people (Many of the countries that have ordered CoronaVac are relatively poor, desperate to halt the pandemic and protect their populations). The weaker efficacy of Chinese CoronaVac from Brazil is identified as a powerful actor causing a setback to Chinese ambitions as a powerful global power. Chinese State media are identified as powerful negative actors playing down the weak data of CoronaVac in Brazil. China is described as a negative country having a history of vaccine quality scandals. Scientists are represented as powerful actors raising questions and concerns about the piecemeal way in which efficacy data about the Chinese vaccines had been released. Verbal processes are widely used in this report. In the report, participants and experts are ideologically chosen saying negative things about Chinese vaccines. The chosen participants are represented as powerful sayers downgrading the efficacy of Chinese coronavirus vaccines and questioning and doubting the usefulness of Chinese vaccines and their older technology. Expanding clause complexing is also ideologically chosen. The report is full of complex sentences, subordinating and coordinating conjunctions, and long sentence patterns. Most of these expansions are employed to emphasize and highlight the negative qualities of Chinese vaccines (The tepid results could also be problematic for Chinese officials, given that they had touted the efficacy of the vaccines made by Sinovac and Sinopharm. Even though the vaccines had not received regulatory approval, and data from late-stage trials had not been made public, Beijing gave them to thousands of Chinese people under an emergency use policy; it plans to vaccinate 50 million people by the middle of next month). Evidentiality is a powerful strategy that can be invested ideologically by language users and at the same time it can uncover hidden ideologies of language users. Most of the evidential markers used in the report are indirect and direct hearsay evidentials. Most of them are indirect hearsay markers such as Brazil says, scientists in Brazil 
have downgraded, officials at the Butantan Institute in São Paulo said, A senior official in Hong Kong said, Scientists had already raised questions, officials say. All of these evidentials are indirect and unnamed making the information source less reliable. Some named experts with their direct quotations are ideologically chosen saying negative things about Chinese vaccines. Even when they say positive things about Chinese vaccines, their positive things are flavoured with negative things. Consider this direct quotation which is said by Natalia Pasternak, a microbiologist and the president of Instituto Questão de Ciência, a Brazilian nongovernmental organization: "It is not the best vaccine in the world," she said at the news conference during which the efficacy rate was disclosed. But she called it a "perfectly acceptable vaccine". Another point that should be mentioned is that when experts say positive things about Chinese vaccines, their speech is indirectly quoted but when they say negative things about Chinese vaccines, their speech is directly quoted making it more factual and reliable: consider these two indirect and direct quotations mentioned which belong to the same person: Denise Garrett, a Brazilian-American epidemiologist and vaccine expert, said there was no reason to doubt CoronaVac's safety but "The lack of transparency really damages people's trust," she said. "They've just reinforced the narrative that this vaccine is not good."

\subsubsection{Report 2}

This report has the following headline: China wanted to show off its vaccines: it's backfiring. The mental verb "want" presents China as a sensor who tries to make people admire its abilities or achievements in the issue of vaccines. The progressive intransitive verb "backfiring" is used to show the reverse of China's desired or expected effect. There is a tendency from the newspaper to convince the public that China's purpose in vaccines is not humanitarian (to eliminate the pandemic and save people's lives) but it is ideological (to show itself as a global power). The headline is negative in nature. There is no positivity in it at all (Table 4).

Like the headline, the news story is also negative towards China. The discourse of negative others (China, Chinese vaccines, Chinese media) is widely used in this report. Negative lexical items such as delays, inconsistent data, spotty disclosures, backlash, slow and spotty, cannot stop the virus, insufficient data, less effective, plagued with doubts, the country's vaccine scandals, lack of openness, shoddy quality, distrustful of a Covid-19 vaccine made in China, spotty and inconsistent disclosures, uncertainty are powerful negative lexis ideologically employed to emphasize the negative qualities of China and its vaccines. In this report, China and its vaccines are always associated with doubtfulness, distrustfulness, and mistrustfulness. Powerful negative adjectives, associated with cunningness, deceitfulness, and deceptiveness, are used to refer to China.

Table 4 The New York times report 2 summary

\begin{tabular}{ll}
\hline Headline & China wanted to show off its vaccines: it's backfiring \\
Length & 1,510 words \\
Key Features & $\begin{array}{r}\text { The report focuses on the negative representation of } \\
\text { China, its vaccines, and media }\end{array}$ \\
\hline
\end{tabular}


In addition to the negative lexis used against China and its vaccines, the newspaper also invests transitivity (processes and participants) ideologically. Chinese vaccines are described as powerful actors disappointing China as an ambitious global power. Officials in Brazil and Turkey are described as powerful sayers complaining about Chinese companies' slow shipment of doses and ingredients. Chinese vaccines are described as weak actors cannot stop the virus. In the Philippines, some lawmakers are identified as powerful sayers criticizing the government's decision of buying a vaccine made by Chinese company, Sinovac. An official in Singapore is identified as a powerful sayer distrusting the Chinese vaccine ("Right now, I would not take any Chinese vaccine, because there's insufficient data," said Bilahari Kausikan, an influential former official at Singapore's Ministry of Foreign Affairs. He added that he would consider it only with "a proper report."). Chinese State media are described as powerful actors starting a misinformation campaign against American vaccines and promoting Chinese vaccines as a better alternative. Using relational process, Chinese vaccines are identified as less effective. Chinese history is identified of having vaccine scandals. Several governments are identified as angry from Beijing's lack of openness. Seventeen countries and regions are identified as distrustful of a Covid-19 vaccine made in China. Using verbal process, Brazil's health minister, Eduardo Pazuello is described as a powerful sayer criticizing China for not acting fast enough with the documents needed to export raw materials to Brazil. Jair Bolsonaro, Brazil's president is described as a powerful sayer criticizing the Chinese vaccine's low efficacy rate. Expanding clause complexing is also used skillfully in this report. The newspaper gives more contextual details and emphases to the negative representation of China and its vaccines. Long compound-complex sentences full of subordinating and coordinating conjunctions are used for only one ideological purpose: to give more negative information about China and its vaccines (China's campaign has been plagued with doubts, however. Many people have memories of the country's vaccine scandals. Several governments remain angry about Beijing's lack of openness about the virus in the early days of the pandemic. Its efforts at the start of last year to distribute masks and protective equipment to the West came under fire amid reports of shoddy quality and the demands by Chinese officials for public thanks). Evidentiality is also invested ideologically in this report. All the sources and quotations used in the report are criticizing China saying negative things about its vaccines. Some sources are not given names. Some others are given names and institutions criticizing China harshly. Most of the information sources about Chinese vaccines are indirect hearsay evidential markers such as officials said, lawmakers said, scientists said. Other sources are direct hearsay evidentials but such direct hearsay sources are skillfully chosen such as the mocking statement said by Jair Bolsonaro, Brazil's president about the low efficacy of the Chinese vaccine. The newspaper selects sources ideologically. For example, two figures opposing the Philippines president, Rodrigo Duterte are selected criticizing the president's wrong administration of favouring Chinese-made vaccines (Risa Hontiveros, an opposition lawmaker, said President Rodrigo Duterte's administration "continues to cram their preference for Chinese-made vaccines down the public's throat, without emergency use approval 
and with inconsistent data." Leila de Lima, a senator and opposition leader who is in prison, expressed anger that the government was paying $\$ 61$ a dose, more than double what Sinovac's partner in Indonesia is paying). No scientific proofs are given except the technology which the Chinese vaccines rely on. According to the report, Chinese vaccine technology is old and traditional.

\section{Conclusions}

Through the analysis of the selected news reports, this article proves that COVID19 vaccines are politicized and used for ideological interests.

Lexicalization is invested ideologically by the two selected newspapers for political interests. In Global Times reports, the positive representation of Chinese vaccines and the negative representation of American vaccines are clearly used. Global Times always says positive things about Chinese vaccines and never says negative things about Chinese vaccines, says negative things about American vaccines and never says positive things about American vaccines. The same is true with The New York Times. The newspaper always says positive things about American vaccines and never says negative things about American vaccines, says negative things about Chinese vaccines and never says positive things about Chinese vaccines. Transitivity is skillfully employed by the two newspapers. In Global Times reports, American vaccines are killers killing more people, weak actors unable to fight the pandemic, expensive, not suiting poor countries, and complex in transportation and storage conditions. Chinese vaccines are powerful actors able to fight the pandemic, cheap suiting poor countries, simple and easy in logistics. Sayers participants, officials and experts are ideologically chosen. They say positive things about Chinese vaccines, while they say negative things about American vaccines. In The New York Times reports, Chinese vaccines are weak actors, less effective, having low efficacy rates in fighting the pandemic, while American vaccines are powerful actors in fighting and eliminating the pandemic with high efficacy rates. Sayers, experts, scientists, lawmakers are also skillfully chosen. They are powerful sayers saying negative things about Chinese vaccines, while they say positive things about American vaccines. Both newspapers invest evidentiality for political and ideological reasons. Most of the evidentials used by both newspapers to negatively represent Chinese vaccines and American vaccines do not contain high degree of reliability in the information source. Most of the used evidentials are indirect hearsay markers with more generalizations such as experts said, scientists said, lawmakers said, and officials said. No scientific proofs are given in the negative news stories of Chinese vaccines and American vaccines.

It can be concluded that COVID-19 vaccines are politicized and used for ideological interests. Science, pandemics, and vaccines must not be politicized. Such ideological politicization creates fear in people's minds, making them hesitant in taking a vaccine. In this case, achieving herd immunity and overcoming the pandemic will definitely become impossible. 


\section{References}

1. Abbas, A.H. 2017. Evidentiality in putin's political speeches on terrorism. Journal of Education College Wasit University 1 (28): 681-708.

2. Abbas, A.H. 2020. Politicizing the pandemic: A schemata analysis of COVID-19 news in two selected newspapers. International Journal for the Semiotics of Law. https://doi.org/10.1007/ s11196-020-09745-2.

3. Adjei, A.A. 2017. The expansion relations of clause complexing (CC) in the editorials of the daily graphic. Journal of Literature, Languages and Linguistics 30: 12-26.

4. Aikhenvald, A. 2004. Evidentiality. Oxford: Oxford University Press.

5. Barker, C., and D. Galasinski. 2001. Cultural studies and discourse analysis: A dialogue on language and identity. London: Sage Publications.

6. Beaumont, P., S. Jones, and K. Wilsher. 2020, May 31. Global report: Fears of coronavirus surge from US protests as world cases hit $6 \mathrm{~m}$. The Guardian. https://www.theguardian.com/world/2020/ may/31/global-report-fears-of-coronavirus-surge-from-us-protests-as-world-cases-hit-6m.

7. Chafe, W. 1986. Evidentiality in english conversation and academic writing. In Evidentiality: The linguistic coding of epistemology, ed. W. Chafe and J. Nichols. Norwood: Ablex Publishing.

8. COCONEL Group. 2020. A future vaccination campaign against COVID-19 at risk of vaccine hesitancy and politicisation. The Lancet Infectious Diseases 20 (7): 769-770. https://doi.org/10.1016/ S1473-3099(20)30426-6.

9. Coronavirus Action Plan: A Guide to What You Can Expect Across the UK. (2020). Department of health and social care. https://www.gov.uk/government/publications/coronavirus-action-plan/coron avirus-action-plan-a-guide-to-what-you-can-expect-across-the-uk.

10. European Centre for Disease Prevention and Control. (2020). https://www.ecdc.europa.eu/sites/ default/files/documents/RRA-outbreak-novel-coronavirus-disease-2019-increase-transmissionglobally-COVID-19.pdf.

11. Ferreri, E. (2021). Vaccines: Herd Immunity, Passports, Reaching the Underserved. Available at https://today.duke.edu/2021/04/vaccines-herd-immunity-passports-reaching-underserved

12. Fowler, R. 1991. Language in the news. London: Routledge.

13. Halliday, M.A.K., and C.M.I.M. Matthiessen. 2004. An introduction to functional grammar. London: Edward Arnold.

14. Halliday, M.A.K. 1994. An introduction to functional grammar, 2nd ed. London: Edward Arnold.

15. Kahane, L.H. 2021. Politicizing the mask: Political, economic and demographic factors affecting mask wearing behavior in the USA. Eastern Econ J 47: 163-183. https://doi.org/10.1057/ s41302-020-00186-0.

16. Latkin, C.A., L. Dayton, G. Yi, A. Konstantopoulos, and B. Boodram. 2021. Trust in a COVID-19 vaccine in the US: A social-ecological perspective. Social science \& medicine 270: 113684. https:// doi.org/10.1016/j.socscimed.2021.113684.

17. Lin, C., P. Tu, and L.M. Beitsch. 2021. Confidence and receptivity for COVID-19 vaccines: A rapid systematic review. Vaccines 9 (1): 16. https://doi.org/10.3390/vaccines9010016.

18. Liu, Z. 2016. Evidentiality in Chinese. International Journal of Linguistics 8 (2): 1-11.

19. Mayr, A. 2008. Language and power: An introduction to institutional discourse. London: Continuum International Publishing Group.

20. Min, S.J. 1997. Constructing ideology: A critical linguistic analysis. Studies in the Linguistic Sciences 27 (2): 147-166.

21. Olowe, J.H.O. (1993). Language and ideology in Nigerian newspapers in the medium of English. Unpublished Ph.D Thesis. Obafemi Awolowo University, Ile Ife, Nigeria.

22. Rothgerber, H., Wilson, T., Whaley, D., Rosenfeld, D. L., Humphrey, M., Moore, A. L. \& Bihl, A. 2020, April 22. Politicizing the COVID-19 pandemic: Ideological differences in adherence to social distancing. https://doi.org/10.31234/osf.io/k23cv

23. Zhang, Rui. 2021. How media politicize COVID-19 lockdowns: A case study comparing frame use in the coverage of Wuhan and Italy lockdowns by the New York times. Media Asia 48 (2): 89-107. https://doi.org/10.1080/01296612.2021.1884518.

24. Saeed, J. 1997. Semantics. Oxford: Blackwell Publishers.

25. Simpson, P. 1993. Language, ideology and point of view. New York: Routledge.

26. Trogen, B., and L.A. Pirofski. 2021. Understanding vaccine hesitancy in COVID-19. Med. https:// doi.org/10.1016/j.medj.2021.04.002. 
27. Van Dijk, T. 1995. Discourse semantics and ideology. Discourse and Society 6 (2): 243-289.

28. Van Dijk, T. 2000. Ideology and discourse: A multidisciplinary introduction. Barcelona: Pompeu Fabra University.

29. Van Dijk, T. 2006. Politics, ideology, and discourse. Encyclopedia of Language and Linguistics. https://doi.org/10.1016/B0-08-044854-2/00722-7.

30. WHO. (2020a). Coronavirus disease (COVID-19): Herd immunity, lockdowns and COVID-19. Available at https://www.who.int/news-room/q-a-detail/herd-immunity-lockdowns-and-covid-19? gclid=EAIaIQobChMIiO741Ob67wIVhOF3Ch2tqA3PEAAYASAAEgLJO_D_BwE\#

31. WHO. (2020b). Managing the COVID-19 infodemic: Promoting healthy behaviours and mitigating the harm from misinformation and disinformation. Available at https://www.who.int/news/item/ 23-09-2020-managing-the-covid-19-infodemic-promoting-healthy-behaviours-and-mitigating-theharm-from-misinformation-and-disinformation

32. WHO. (2020c). Infodemic management: Infodemiology. Available at: https://www.who.int/teams/ risk-communication/infodemic-management

33. Wolfe, R.M., and L.K. Sharp. 2002. Anti-vaccinationists past and present. Bmj 325 (7361): $430-432$.

\section{Global Times Reports}

34. Why were US media silent on Pfizer vaccine deaths? https://www.globaltimes.cn/page/202101/ 1212939.shtml

35. China's vaccines better suit Africa, LatAm due to 'lower costs, easier logistics' https://www.globa ltimes.cn/content/1208668.shtml

\section{The New York Times Reports}

36. Disappointing Chinese vaccine results pose setback for developing world https://www.nytimes.com/ 2021/01/13/business/chinese-vaccine-brazil-sinovac.html

37. China wanted to show off its vaccines: it's backfiring https://www.nytimes.com/2021/01/25/busin ess/china-covid-19-vaccine-backlash.html

Publisher's Note Springer Nature remains neutral with regard to jurisdictional claims in published maps and institutional affiliations. 